\title{
A review and update on the use of Hibiscus sabdariffa (karkadeh) in the treatment of essential hypertension
}

${ }^{1}$ Primary Health Care Corporation, Doha, Qatar

${ }^{2}$ The Royal College of Surgeons in Ireland - Medical University of Bahrain, Busaiteen, Kingdom of Bahrain

A - Study Design, B - Data Collection, C - Statistical Analysis, D - Data Interpretation, E - Manuscript Preparation, F - Literature Search, G - Funds Collection

Summary Background. Essential hypertension is a common, significant worldwide disease whose adequate treatment requires a multidrug regime in $70 \%$ of patients, where adherence to treatment ranges from low to very low $(72.7 \%$ to $19.7 \%)$, and where each additional medication used causes a decrease in adherence by up to $85 \%$. Hibiscus sabdariffa L. (HS) is a widely used herb which has been used for its antihypertensive effect, which may offer to play a useful synergistic role to pharmacotherapy.

Objectives. This review sought to identify relevant basic laboratory studies, human randomised controlled studies (RCTs), meta-analysis and reviews studying the safety, mechanism and/or effect of HS on blood pressure.

Material and methods. A search was done, ending on the 1st of October 2019, of the following databases: Medline, COCHRANE and EMBASE. RCTs were assessed for quality using the Jadad scale.

Results. Basic laboratory studies have shown that HS is rich in bioactive anthocyanins, which inhibit angiotensin-converting enzyme (ACE) in a dose-dependent manner, and HS extracts also have a direct vasodilator effect. 13 safety studies have found HS to be safe at normal doses with minimal clinically important drug-herb interaction. Very high doses (>300 mg/kg/day) are associated with liver enzyme abnormalities and raised uric acid in rat studies. 14 RCTs show that HS causes a significant reduction in systolic blood pressure $(-6.3$ to $-31.9 \mathrm{~mm} \mathrm{Hg})$ and diastolic blood pressure $(-1.1$ to $-19.7 \mathrm{~mm} \mathrm{Hg})$

Conclusions. HS is a widely available, acceptable, cheap and effective synergistic agent in the management of essential hypertension. Key words: essential hypertension, hibiscus, therapeutics.

Hashmi T, Zidan M, Khudadad H, Hashmi Y. A review and update on the use of Hibiscus sabdariffa (karkadeh) in the treatment of essential hypertension. Fam Med Prim Care Rev 2020; 22(3): 240-243, doi: https://doi.org/10.5114/fmpcr.2020.98253.

\section{Background}

Hypertension is one of the most common diseases in the world, with a global prevalence estimated to be $31 \%$ [1] and a similar prevalence in Arab countries at $29.5 \%$ [2], with an annual incidence of $8.6 \%$ in men and $8.2 \%$ in women [3]. With a mortality rate of $13 \%$, it is one of the leading causes of death [2]. Many patients (almost 70\%) fail to reach therapeutic targets ( $<140 / 90 \mathrm{~mm} \mathrm{Hg}$ ) with monotherapy, and polytherapy is required for effective control [4].

\section{The challenge of adherence}

Adherence to treatment is poor. Medication event monitors show that half of patients stop treatment within a year, and $48 \%$ have a drug holiday - a cessation of medication for three or more days, especially on weekends [5]. A study conducted in Poland showed that while most patients $(72.7 \%)$ are adherent with their anti-hypertensives, it is halved if they are on polytherapy compared to those on monotherapy [6]. Studies looking at urinary and serum metabolites of medication as a markers of adherence have shown adherence rates to antihypertensive medication to be $58.4 \%$ in the UK and $68.5 \%$ in the Czech Republic, with nonadherence increasing by $85 \%$ (UK) and 77\% (Czech) for each additional antihypertensive medication [7]. Data from the Middle East area is similarly low: Jordan and Lebanon 55.9\% [8], while in Saudi Arabia, the rate of adherence in females is $59 \%$, but is significantly lower in males at $19.7 \%$ [9].
Attitude of patients and doctors to herbal treatments

Over $25 \%$ of patients with hypertension reported the use of herbal medication based on recommendations from family and friends with little information from doctors [10]. Compliance for non-pharmacological therapy for hypertension is relatively higher [6]. Hypertensive patients have a higher likelihood of using herbal treatments [11]. Usage of herbal treatments is widespread, especially in low-income countries [12], and they are widely available over the counter, through the web and even in popular markets [13]. Herbs are considered "natural products", and patient adherence to herbal treatments is higher, and they report a better quality of life [14].

The majority of family physicians have a negative view of the effectiveness of herbal medicine [15], and they are apprehensive of their safety due to poor regulation by authorities [13]. Case reports of hepatotoxicity and occasional deaths associated with some herbs, such as Polygonum multiflorum Thunb. (tuber fleeceflower), support a blanket 'do no harm' approach [16].

\section{A combined approach}

In recognition of the World Health Organisation's Traditional Medicine strategy [17] to "strengthen the role traditional medicine plays in keeping populations healthy", this article aims to provide an update and review of the latest research on Hibiscus sabdariffa L. (HS), a traditional herb thought to have originated in India or Africa [18]; its common names are roselle and 
karkadeh in Arabic. HS offers a potentially synergistic effect with traditional pharmacotherapy, which family doctors may be able to draw upon when offering lifestyle and dietary advice to patients, especially for those that are reluctant to climb the ladder of pharmacological treatments.

\section{Methods}

The need for approval was ascertained from the Primary Health Care Corporation Research subcommittee, who advised that ethical approval was not required. The following databases were searched for relevant publications prior to October 2019 by the first two authors: Medline via PubMed, EMBASE, Cochrane Central Register of Controlled Trials. The search strategy used is given by the following nested Boolean string: ((*hypertens*[Title]) OR (essential hypertension[Title]) OR (blood pressure[Title]) OR (Essential Hypertension[MeSH Terms]) OR (Hypertension[MeSH Terms]) OR) AND ((hibiscus*[Title]) OR (sabdariffa*[Title]) OR (roselle*[Title]) OR (karkad*[Title])).

Studies included in this review were human RCTs, meta-analyses, reviews and interventional trials. Studies over 10 years old, case reports and non-English publications were excluded.

\section{Results}

\section{Biological mechanism of action}

HS contains bioactive anthocyanins, responsible for the red, purple and blue colours in the plants. Anthocyanins inhibit platelet aggregation, cause vasorelaxation, have antioxidant activity, reduce cellular lipid peroxidation and improve lipid profiles [19]. HS calyces are rich in anthocyanins $(622.91 \mathrm{mg} / 100 \mathrm{~g})$ [20], with good antioxidant capacity [21].

Two anthocyanins extracted from HS delphinidin-3-O-sambubioside and cyanidin-3-O-sambubioside inhibit angiotensinconverting enzyme (ACE) activity by competing with the active site in a dose-dependent manner, with an average $50 \%$ inhibitory concentration on ACE function (IC ${ }_{50}$ ) of $132.55 \mu \mathrm{M}$ [22]. Compared to the IC for captopril $23 \mathrm{nM}$ [23], they are weak inhibitors of ACE function.

Other mechanisms include a direct vasodilator effect mediated by an endothelium-derived nitric oxide-cGMP-relaxant pathway and inhibition of calcium $(\mathrm{Ca}(2+))$-influx into vascular smooth muscle cells [24] and activation of endothelial nitric oxide synthase [25]. Acute consumption of HS also increases flow mediated dilatation of the brachial artery [26].

\section{Safety and drug interaction}

Data from 13 studies shows that HS has little effect on liver enzymes, electrolytes and trace elements, except at very high doses of greater than $300 \mathrm{mg} / \mathrm{kg} /$ day over 3 months, which had an adverse impact of liver enzymes and increased uric acid levels in rat studies [27]. The LD50 for HS ranges from 2,000 to $5,000 \mathrm{mg} / \mathrm{kg} /$ day [27] as compared to the LD50 for caffeine at $367 \mathrm{mg} / \mathrm{kg}$ [28]. Typical daily doses used in HS RCTs have been $9 \mathrm{mg} / \mathrm{kg}$ [29], $14 \mathrm{mg} / \mathrm{kg}$ [30] up to $17 \mathrm{mg} / \mathrm{kg}$ [31]. HS infusion and powdered extracts are very likely to be safe when used in the dosages studied, though caution may be needed in patients with hepatic pathology and gout.

\section{HS-drug interaction}

HS increases the diuretic effect and slows elimination of hydrochlorothiazide in a dose-dependent manner [32]. Human volunteer studies show that it slows the elimination of acetaminophen by $11.69 \%$ [33]. In vitro studies show a minimal impact on cytochrome P450 isoenzymes and the pharmacodynamics of caffeine [34]. Current data shows no clinically relevant HS-drug interactions.

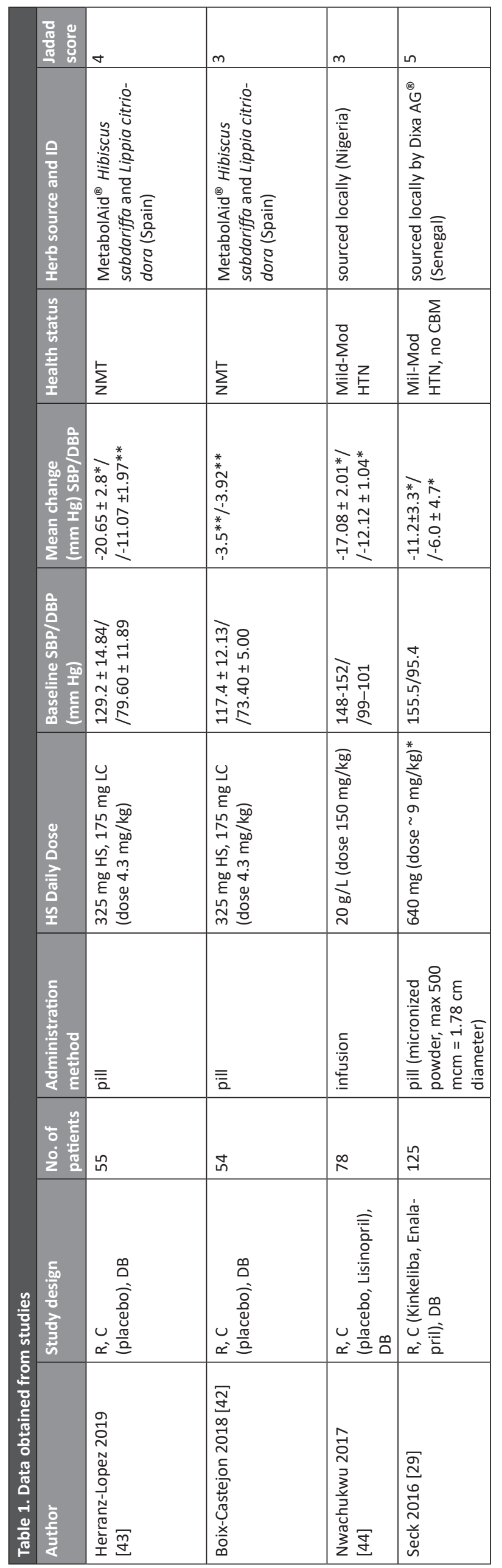




\section{Antihypertensive effect}

Studies on rats show a reduction in both systolic blood pressure (SBP) and diastolic blood pressure (DBP) (SBP $139.6 \pm 1.6$ $\mathrm{mm} \mathrm{Hg}$ vs $174 \pm 2.4 \mathrm{~mm} \mathrm{Hg}, n=5 ; p<0.001$ Intervention vs Control) [35]. The first human trial in 1999 showed a reduction in SBP/ /DBP (SBP -11.2\%; DBP -10.7\%) after 12 days of treatment [36].

A 2009 Cochrane review of literature did not identify any RCTs that met their inclusion criteria requiring a placebo controlled trial [37]. Three other systematic reviews and one metaanalysis have reviewed literature on the treatment of hypertension with HS $[27,38,39]$; the number of unique RCTs was five, all with positive outcomes for the effect of HS on SBP and DBP. A previous review of literature done in 2016 identified ten RCTs and included those previously identified by the last three reviews [40]. Six of the ten papers scored 3 on the Jadad scale for RCTs, implying a reasonable quality. Two of these were placebo controlled RCTs. All ten studies showed a significant decrease in SBP ( -6.3 to $-31.9 \mathrm{~mm} \mathrm{Hg}$ ), and nine studies showed a decrease in DBP (-1.1 to $-19.7 \mathrm{~mm} \mathrm{Hg}$ ). Both placebo controlled studies also showed a decrease in SBP/DBP (-7.2/-3.1 mm Hg [31], -17/ /-11.2 mm Hg [41]).

Since 2010, there have been four further RCTs, whose findings are summarised in Table 1 . Three of the four studies had a placebo arm, and all four showed a significant and positive effect on lowering SBP/DBP (-3.5 to -20.5/-3.92 to $-12.12 \mathrm{~mm} \mathrm{Hg}$ ).
The lowest decrease was seen in subjects who had baseline normotensive blood pressures [42]. There was significant heterogeneity in the form of HS used: powder versus infusions. The most methodologically robust trial, with a Jadad score of 5 with allocation blinding and the largest number of participants, showed a significant decrease in SBP/DBP $(-11.2 \pm 3.3(p<0.001)-6.0 \pm$ $4.7(p<0.001) \mathrm{mm} \mathrm{Hg}$ ) compared to the placebo [29].

\section{Discussion}

Although 14 RCTs have now been conducted to-date there is significant variation in trial design and quality, dosage preparation and form of HS used, method used to determine the dosage and patient type enrolled in the studies. The degree of heterogeneity prevents a valid meta-analysis. Based on published data and an expected magnitude of effect of $10 \mathrm{~mm} \mathrm{Hg}$ reduction in SBP, an adequately powered RCT will at least require 102 patients [45]. To date, only two trials have crossed this threshold of enrolment with 193 patients: Herrera et al., who used an extract of HS [46], and Seck et al., who used micronized HS in pill form [28] with 125 patients. The current data is encouraging and suggests that HS is a biologically plausible and beneficial dietary option that can act synergistically in the treatment of essential hypertension. Further adequately powered and aligned trials are required to strengthen the evidence base.

Source of funding: This work was funded from the authors' own resources.

Conflicts of interest: The authors declare no conflicts of interest.

\section{References}

1. Mills KT, Bundy JD, Kelly TN, et al. Global disparities of hypertension prevalence and control: a systematic analysis of population-based studies from 90 countries. Circulation 2016; 134(6): 441-450, doi: 10.1161/CIRCULATIONAHA.115.018912.

2. Tailakh A, Evangelista LS, Mentes JC, et al. Hypertension prevalence, awareness, and control in Arab countries: a systematic review. Nurs Health Sci 2014; 16(1): 126-130, doi: 10.1111/nhs.12060.

3. Lacruz ME, Kluttig A, Hartwig S, et al. Prevalence and incidence of hypertension in the general adult population: results of the CARLACohort Study. Medicine 2015; 94(22): e952, doi: 10.1097/MD.00000000000000952.

4. Guerrero-García C, Rubio-Guerra AF. Combination therapy in the treatment of hypertension. Drugs Context 2018; 7: 212531, doi: 10.7573/dic.212531.

5. Vrijens $B$, Vincze $G$, Kristanto $P$, et al. Adherence to prescribed antihypertensive drug treatments: longitudinal study of electronically compiled dosing histories. BMJ 2008; 336(7653): 1114-1117, doi: 10.1136/bmj.39553.670231.25.

6. Paczkowska A, Kopciuch D, Nowakowska E, et al. Compliance among adolescents with arterial hypertension. Adv Clin Exp Med 2016; 25(3): 441-448, doi: 10.17219/acem/33838.

7. Gupta P, Patel P, Štrauch B, et al. Risk factors for nonadherence to antihypertensive treatment. Hypertension 2017; 69(6): 1113-1120, doi: 10.1161/hypertensionaha.116.08729.

8. Alhaddad IA, Hamoui O, Hammoudeh A, et al. Treatment adherence and quality of life in patients on antihypertensive medications in a Middle Eastern population: adherence. Vasc Health Risk Manag 2016; 12: 407-413, doi: 10.2147/VHRM.S105921.

9. Abdelhalim HN, Zahrani Al, Shuaibi AM. Factors affecting treatment compliance of patients on antihypertensive therapy at National Guard Health Affairs (NGHA) Dammam Primary Health Care Clinics (PHCC). J Family Community Med 2019; 26(3): 168-172, doi: 10.4103/jfcm.JFCM_43_19.

10. Rahmawati R, Bajorek BV. Self-medication among people living with hypertension: a review. Fam Pract 2017; 34(2): 147-153, doi: 10.1093/fampra/cmw137.

11. Aykan DA, Aykan AC. Factors associated with the concomitant use of cardiovascular drugs and dietary herbal products: a cross-sectional study. J Cardiovasc Pharmacol Ther 2018, doi: 10.1177/1074248418794938.

12. Chrysant SG, Chrysant GS. Herbs used for the treatment of hypertension and their mechanism of action. Curr Hypertens Rep 2017; 19(9): 77, doi: 10.1007/s11906-017-0775-5.

13. Chrysant SG. The clinical significance and costs of herbs and food supplements used by complementary and alternative medicine for the treatment of cardiovascular diseases and hypertension. J Hum Hypertens 2016; 30(1): 1-6, doi: 10.1038/jhh.2015.42.

14. Souza ACC de, Borges JWP, Moreira TMM. Quality of life and treatment adherence in hypertensive patients: systematic review with meta-analysis. Rev Saude Publica 2016; 50: 71, doi: 10.1590/S1518-8787.2016050006415.

15. Fries CJ. Classification of complementary and alternative medical practices: Family physicians' ratings of effectiveness. Can Fam Physician 2008; 54(11): 1570-1571.

16. Lei X, Chen J, Ren J, et al. Liver damage associated with Polygonum multiflorum Thunb.: a systematic review of case reports and case series. Evid Based Complement Alternat Med 2015; 2015: 459749, doi: 10.1155/2015/459749.

17. World Health Organization. WHO traditional medicine strategy: 2014-2023. 2015 Nov 20 [cited 2.09.2019]. Available from URL: http:// www.who.int/medicines/publications/traditional/trm_strategy14_23/en/.

18. Da-Costa-Rocha I, Bonnlaender B, Sievers H, et al. Hibiscus sabdariffa L. - a phytochemical and pharmacological review. Food Chemistry 2014; 165: 424-443, doi: 10.1016/j.foodchem.2014.05.002.

19. Khoo HE, Azlan A, Tang ST, et al. Anthocyanidins and anthocyanins: colored pigments as food, pharmaceutical ingredients, and the potential health benefits. Food Nutr Res 2017; 61(1): 1361779, doi: 10.1080/16546628.2017.1361779. 
20. Abou-Arab AA, Abu-Salem FM, Abou-Arab EA. Physico-chemical properties of natural pigments (anthocyanin) extracted from Roselle calyces (Hibiscus sabdariffa). J Am Sci 2011; 7(7): 445-446.

21. Wu H-Y, Yang K-M, Chiang P-Y. Roselle anthocyanins: antioxidant properties and stability to heat and pH. Molecules 2018; 23(6): 1357, doi: $10.3390 /$ molecules23061357.

22. Ojeda $D$, Jiménez-Ferrer $E$, Zamilpa $A$, et al. Inhibition of angiotensin convertin enzyme (ACE) activity by the anthocyanins delphinidin- and cyanidin-3-O-sambubiosides from Hibiscus sabdariffa. J Ethnopharmacol 2010; 127(1): 7-10, doi: 10.1016/j.jep.2009.09.059.

23. Barrett GC, Elmore DT. Amino Acids and Peptides. Available from URL: https://books.google.com/books/about/Amino_Acids_and_ Peptides.html?id=9Np_Yue4-vgC

24. Ajay M, Chai HJ, Mustafa AM, et al. Mechanisms of the anti-hypertensive effect of Hibiscus sabdariffa L. calyces. J Ethnopharmacol 2007; 109(3): 388-393, doi: 10.1016/j.jep.2006.08.005.

25. Sarr M, Ngom S, Kane MO, et al. In vitro vasorelaxation mechanisms of bioactive compounds extracted from Hibiscus sabdariffa on rat thoracic aorta. Nutr Metab 2009; 6: 45, doi: 10.1186/1743-7075-6-45.

26. Abubakar SM, Spencer JPE, Lovegrove JA. Acute impact of Hibiscus sabdariffa calyces on postprandial lipids, biomarkers of insulin resistance and inflammation in humans. Proc Nutr Soc 2016;75(OCE3). Available from URL: https://www.cambridge.org/core/services/ aop-cambridge-core/content/view/E4AF2A22F6453C3BBA8E865359B09FB9/S0029665116001245a.pdf/div-class-title-acute-impactof-span-class-italic-hibiscus-sabdariffa-span-calyces-on-postprandial-lipids-biomarkers-of-insulin-resistance-and-inflammation-in-humans-div.pdf.

27. Hopkins AL, Lamm MG, Funk JL, et al. Hibiscus sabdariffa L. in the treatment of hypertension and hyperlipidemia: a comprehensive review of animal and human studies. Fitoterapia 2013; 85: 84-94, doi: 10.1016/j.fitote.2013.01.003.

28. Adamson RH. The acute lethal dose 50 (LD50) of caffeine in albino rats. Regul Toxicol Pharmacol 2016; 80: 274-276, doi: 10.1016/j. yrtph.2016.07.011.

29. Seck SM, Diop AE, Ka FE, et al. SP106 Antihypertensive efficacy of Combretum micranthum and Hibiscus sabdariffa: a randomized controlled trial versus Ramipril. Nephrology Dialysis Transplantation 2016; 31: i120-i120, doi: 10.1093/ndt/gfw159.15.

30. Kuriyan R, Kumar DR, Rajendran R, et al. An evaluation of the hypolipidemic effect of an extract of Hibiscus sabdariffa leaves in hyperlipidemic Indians: a double blind, placebo controlled trial. BMC Complement Altern Med 2010; 10: 27, doi: 10.1186/1472-6882-10-27.

31. McKay DL, Chen C-YO, Saltzman E, et al. Hibiscus sabdariffa L. tea (tisane) lowers blood pressure in prehypertensive and mildly hypertensive adults. J Nutr 2010; 140(2): 298-303, doi: 10.3945/jn.109.115097.

32. Ndu OO, Nworu CS, Ehiemere CO, et al. Herb-drug interaction between the extract of Hibiscus sabdariffa L. and hydrochlorothiazide in experimental animals. J Med Food 2011; 14(6): 640-644, doi: 10.1089/jmf.2010.0117.

33. Kolawole JA, Maduenyi A. Effect of zobo drink (Hibiscus sabdariffa water extract) on the pharmacokinetics of acetaminophen in human volunteers. Eur J Drug Metab Pharmacokinet 2004; 29(1): 25-29, doi: 10.1007/BF03190570.

34. Showande JS, Igbinoba SI, Kajula M, et al. In vitro modulation of cytochrome P450 isozymes and pharmacokinetics of caffeine by extracts of Hibiscus sabdariffa Linn calyx. J Basic Clin Physiol Pharmacol 2019; 30(3), doi: 10.1515/jbcpp-2018-0206.

35. Odigie IP, Ettarh RR, Adigun SA. Chronic administration of aqueous extract of Hibiscus sabdariffa attenuates hypertension and reverses cardiac hypertrophy in 2K-1C hypertensive rats. J Ethnopharmacol 2003; 86(2-3): 181-185, doi: 10.1016/s0378-8741(03)00078-3.

36. Haji Faraji M, Haji Tarkhani A. The effect of sour tea (Hibiscus sabdariffa) on essential hypertension. J Ethnopharmacol 1999; 65(3): 231-236, doi: 10.1016/s0378-8741(98)00157-3.

37. Ngamjarus C, Pattanittum P, Somboonporn C. Roselle for hypertension in adults. Cochrane Database Syst Rev 2010; 2010(1): CD007894, doi: 10.1002/14651858.CD007894.

38. Wahabi HA, Alansary LA, Al-Sabban AH, et al. The effectiveness of Hibiscus sabdariffa in the treatment of hypertension: a systematic review. Phytomedicine 2010; 17(2): 83-86, doi: 10.1016/j.phymed.2009.09.002.

39. Serban C, Sahebkar A, Ursoniu S, et al. Effect of sour tea (Hibiscus sabdariffa L.) on arterial hypertension: a systematic review and metaanalysis of randomized controlled trials. J Hypertens 2015; 33(6): 1119-1127, doi: 10.1097/HJH.0000000000000585.

40. Walton RJ, Whitten DL, Hawrelak JA. The efficacy of Hibiscus sabdariffa (rosella) in essential hypertension: a systematic review of clinical trials. AJHM 2016; 28(2): 48-51.

41. Nwachukwu DC, Aneke E, Nwachukwu NZ, et al. Effect of Hibiscus sabdariffaon blood pressure and electrolyte profile of mild to moderate hypertensive Nigerians: a comparative study with hydrochlorothiazide. Niger J Clin Pract 2015; 18(6): 762-770, doi: 10.4103/11193077.163278.

42. Boix-Castejón M, Herranz-López M, Pérez Gago A, et al. Hibiscus and lemon verbena polyphenols modulate appetite-related biomarkers in overweight subjects: a randomized controlled trial. Food Funct 2018; 9(6): 3173-3184, doi: 10.1039/c8fo00367j.

43. Herranz-López M, Olivares-Vicente M, Boix-Castejón M, et al. Differential effects of a combination of Hibiscus sabdariffa and Lippia citriodora polyphenols in overweight/obese subjects: a randomized controlled trial. Sci Rep 2019; 9(1): 1-12, doi: 10.1038/s41598019-39159-5.

44. Nwachukwu DC, Aneke EI, Nwachukwu NZ, et al. Does consumption of an aqueous extract of Hibscus sabdariffa affect renal function in subjects with mild to moderate hypertension? J Physiol Sci 2017; 67(1): 227-234, doi: 10.1007/s12576-016-0458-z.

45. Kane SP, Phar BCPS. Sample Size Calculator [cited 28.10.2019]. Available from URL: https://clincalc.com/stats/samplesize.aspx.

46. Herrera-Arellano A, Miranda-Sánchez J, Avila-Castro P, et al. Clinical effects produced by a standardized herbal medicinal product of Hibiscus sabdariffa on patients with hypertension. A randomized, double-blind, lisinopril-controlled clinical trial. Planta Med 2007; 73(1): 6-12, doi: 10.1055/s-2006-957065.

Tables: 1

Figures: 0

References: 46

Received: 05.11.2019

Reviewed: 19.11 .2019

Accepted: 17.02.2020

Address for correspondence:

Taqi Hashmi, MD

Primary Health Care Corporation

P.O. Box 26555 Doha, Qatar

Tel.: + 97433392900

E-mail: thashmi@phcc.gov.qa 